\title{
SOCIO-DEMOGRAPHIC, EMPLOYMENT, AND INJURY CHARACTERISTICS OF WORKERS INVOLVED IN ROAD TRAFFIC CRASH
}

\author{
Titi Rahmawati Hanedon, Nurrul Hafeezah binti Sahak, Kulanthayan KC \\ Mani, Krishna Gopal Rampal, Kathirkamanathan a/1 S. Vythalingam
}

Department of Community Health, Faculty of Medicine \& Health Sciences, Universiti Putra Malaysia

\begin{abstract}
Background: Workers involved in road traffic crash (RTC) often suffer from injuries that need time to recover. Work rehabilitation with the intention of returning them to work faster is necessary to prevent them from losing their income and affecting productivity. The Social Security Organization of Malaysia (SOCSO) provides such service as part of their compensation benefits to injured workers. The aim of the study was to evaluate the effectiveness of such programs to reduce the number of sick leaves of workers at post RTC.

Subjects and Method: This was a randomized control trial (RCT) conducted in Selangor and Kuala Lumpur, Malaysia. A total of 200 workers was selected for this study from a list of names in the SOCSO claimants, and randomly allocated into two groups: intervention and control groups. The subjects' inclusion criteria were participated in Return to Work Program of SOCSO, vehicle user, and still on medical leave periods. The dependent variable was injury characteristic. The independent variables were socio-demographic and employment. The data were reported descriptively.

Results: A total of 93\% workers had body fracture. The most affected parts were lower limbs (48.5\%), followed by upper limbs (38\%). Lower limbs injury took longer to recover and without rehabilitation affected, workers will be longer under medical leave. Male gender, young workers, and low education increased the risk of RTC.

Conclusion: Information on the socio-demographic, employment, and injury characteristics of post RTC workers can be used to plan preventive programs to reduce RTC incidents. Effective vocational rehabilitation to return them to work faster will improve healing process and maintain productivity.
\end{abstract}

Keywords: injury, socio-demographic, employment, road traffic crash

\section{Correspondence:}

Titi Rahmawati Hanedon. Universiti Putra Malaysia. Email: titi_rahmawati2006@yahoo.co.uk. Mobile: +60126498088 . 